EXTENDED REPORT

\title{
Incidence and prevalence of complaints of the neck and upper extremity in general practice
}

\author{
S D M Bot, J M van der Waal, C B Terwee, D A W M van der Windt, F G Schellevis, L M Bouter, \\ J Dekker
}

See end of article for authors' affiliations

.....................

Correspondence to: Dr Sandra D M Bot Institute for Research in Extramural Medicine, VU University Medical Centre De Boelelaan 1105, 1081 HV Amsterdam Netherlands; s.bot@vumc.nl

Accepted 9 May 2004

\begin{abstract}
Objective: To study the incidence and prevalence of neck and upper extremity musculoskeletal complaints in Dutch general practice.

Methods: Data were obtained from the second Dutch national survey of general practice. In all, 195 general practitioners (GPs) from 104 practices across the Netherlands recorded all contacts with patients during 12 consecutive months. Incidence densities and consultation rates were calculated.

Results: The total number of contacts during the registration period of one year was 1524 470. The most commonly reported complaint was neck symptoms (incidence 23.1 per 1000 person-years), followed by shoulder symptoms (incidence 19.0 per 1000 person-years). Sixty six GP consultations per 1000 personyears were attributable to a new complaint or new episode of complaint of the neck or upper extremity (incidence density). In all, the GPs were consulted 147 times per 1000 registered persons for complaints of the neck or upper extremity. For most complaints the incidence densities and consultation rates were higher for women than for men.

Conclusions: Neck and upper extremity symptoms are common in Dutch general practice. The GP is consulted approximately seven times each week for a complaint relating to the neck or upper extremity; of these, three are new complaints or new episodes. Attention should be paid to training GPs to deal with neck and upper limb complaints, and to research on the prognosis and treatment of these common complaints in primary care.
\end{abstract}

$\mathrm{N}$ eck or upper extremity complaints are a common reason for consulting a general practitioner (GP). It has been estimated that the 12 month period prevalence of neck pain is $31.4 \%$, of shoulder pain $30.3 \%$, of elbow pain $11.2 \%$, and of wrist or hand pain $17.5 \%$ in the general population of the Netherlands. ${ }^{1}$ Roughly $30-40 \%$ of people reporting musculoskeletal pain during the past year indicated that they had contacted their GP for these complaints.

Despite the high prevalence of complaints of the neck and upper extremity in the general population, detailed information on the number of GP consultations attributable to these complaints is scarce. In Finland, musculoskeletal pain was found to be the reason for approximately $18 \%$ of the visits to health centre doctors ${ }^{2}$ and $9.3 \%$ in Iceland. ${ }^{3}$ In England and Wales, $15 \%$ of all registered patients consulted their GP for a disorder of the musculoskeletal system. ${ }^{4}$ These figures refer to musculoskeletal complaints in general and do not tell us about the number of consultations attributable to different types of complaint. There is a need for information on the number of consultations attributable to neck and upper extremity complaints, for the following reasons.

First, the incidence of neck and upper extremity complaints in general practice informs us about the burden of these complaints in the general population-in other words, the number of people with neck and upper extremity complaints that are serious, painful, or annoying enough to seek medical care. In the Netherlands, nearly every citizen is registered with a GP practice. An important feature of the Dutch health care system is that patients see their GP first before going to a specialist. The GP acts as a gatekeeper in the health care system. Referrals to the second or third level of care can, in principle, only be made by the GP. Therefore GP consultation rates provide a good representation of the number of people seeking medical care.
Second, data on the prevalence of neck and upper extremity complaints help us to identify the patient categories that are responsible for the main GP workload caused by these complaints. This information could be used to estimate the pool of demand for health care for neck and upper extremity complaints in general practice, and the need for training of GPs to deal with these complaints. Only one study has presented information on the number of patients seeking medical care for musculoskeletal complaints in relation to anatomical location, age, and sex, ${ }^{2}$ but this study was carried out in rural districts in Finland. The results, therefore, may not easily be transferred to more densely populated areas in industrialised countries.

The way people are insured may have an effect on the number of GP consultations. In the Netherlands, persons whose annual salary is below a statutory ceiling and all recipients of social security benefits have public compulsory health insurance. Patients with public health insurance are reimbursed in full for a GP consultation, while private health insurance policies usually require some co-payments for medical care. People with a public health insurance consult the GP more often than people with a private health insurance; it is expected that this will also be true for neck and upper extremity complaints. About $64 \%$ of the Dutch population have public health insurance and about 36\% have private health insurance. $^{5}$

The large majority of Dutch GPs use computerised patient records. These records provide an excellent opportunity to study the occurrence of diseases of interest in general practice. In 2001 a large survey was conducted among 195 GPs in the Netherlands (the second Dutch national survey of

Abbreviations: ICPC, International Classification of Primary Care; WONCA, World Organisation of Family Doctors 


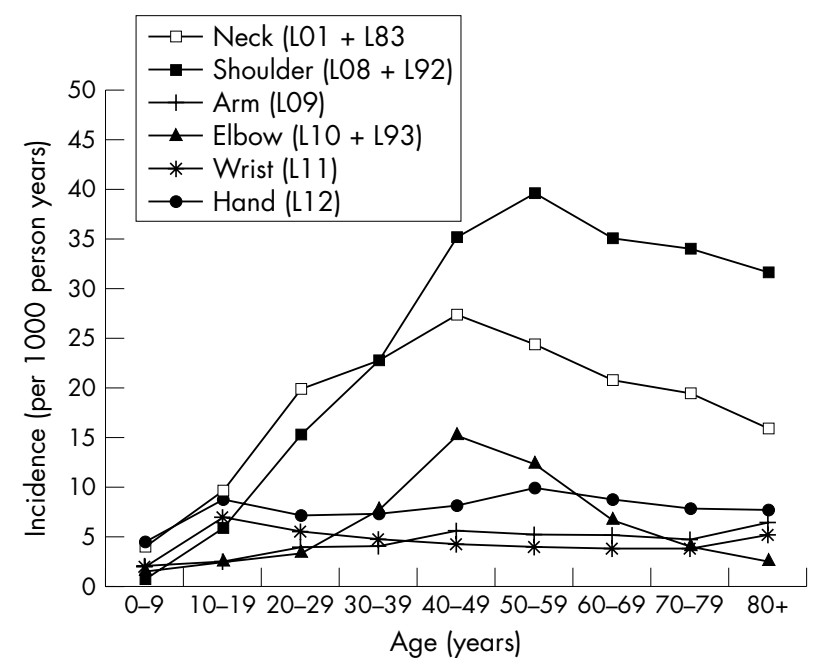

Figure 1 Incidence of neck and upper extremity disorders in relation to anatomical location.

general practice).$^{67}$ The aim of our study was to use the results of this large survey to examine the current incidence and prevalence of neck and upper extremity musculoskeletal complaints in Dutch general practice.

\section{METHODS}

The data used in this study originate from the second Dutch national survey of general practice carried out by the Netherlands Institute for Health Services Research in cooperation with the National Information Network of General Practice in 2001.67 For this survey 195 GPs in 104 practices recorded all contacts with patients during 12 consecutive months.

The participating GPs were distributed all over the Netherlands. They formed a representative sample of the population of all GPs in the Netherlands according to age and sex of the GP, region, and location of the practice (rural/ urban; deprived area); only the percentage of solo practices was smaller than in the total population of Dutch GPs. ${ }^{67}$ The total practice population consisted of 391294 patients at the start of the survey. The population characteristics corresponded very well to the Dutch population as a whole with respect to age, sex, and the type of health insurance. ${ }^{67}$

All contacts were recorded in computer based patient records. The GPs classified the symptoms or diagnosis of each patient at each consultation according to the International Classification of Primary Care (ICPC) ${ }^{8}$ This classification is designated by the World Organisation of Family Doctors (WONCA) as the ordering principle of the family practice domain. ${ }^{8}$ The ICPC classification is made up of a letter followed by a number. The letter stands for the location (for example, $\mathrm{L}=$ musculoskeletal system) and the number stands for different components (that is, symptoms/complaints (codes 1-29), or diagnosis/diseases (codes 70-99)). A selection of ICPC codes from the L chapter was made to identify patients with neck or upper extremity musculoskeletal complaints (see the appendix). Sixty one of the 104 general practices included in the study were already members of the National Information Network of General Practice before the start of the second Dutch national survey, and thus were used to ICPC coding. All GPs were offered a course in the use of the ICPC classification before the start of the study. In a Vignettes study, the mean agreement between GPs and four ICPC experts on 30 cases was $81 \% .^{9}$ The GP recorded if the patient's visit was about a new complaint or a new

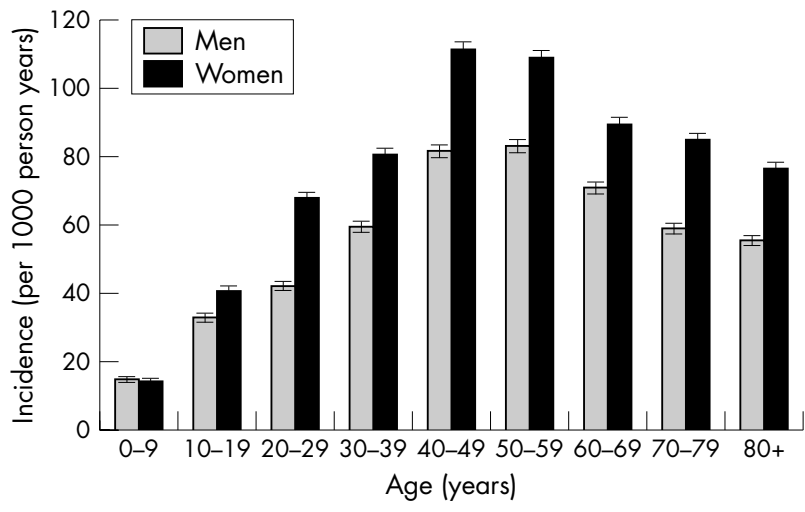

Figure 2 Sex and age specific incidence densities of neck and upper extremity musculoskeletal disorders (ICPC codes L01, L08-L12, L83, L92-L93).

episode of a complaint, and if it was the first or a subsequent consultation of an episode. An episode was considered to be new if the GP regarded it as being separate from earlier problems.

To determine the incidence density we calculated the number of patients with a first new episode of a neck or upper extremity complaint in the study year, divided by the sum of person-years at risk. The incidence densities were calculated for each ICPC code separately. Patients contributed person-years to the denominator until they consulted their GP with a first new episode of a complaint of the neck or upper extremity, after which they were no longer at risk for that specific complaint. However, they were still considered to be at risk for other upper extremity complaints (other ICPC codes). Patients who did not consult the GP for a complaint of the neck or upper extremity contributed 1 person-year to the denominator.

The incidence density was calculated per 1000 personyears, grouped by age, sex, and health insurance. First, a combination of ICPC codes of symptoms and diagnoses of the same anatomical location is presented (that is, neck symptoms (L01) + syndrome of cervical spine (L83); shoulder symptoms (L08) + shoulder syndrome (L92); and elbow symptoms (L10) + tennis elbow (L93)). This gives an impression of the number of patients with a neck or upper extremity complaint per anatomical location. Subsequently, the incidence densities for each of neck and upper extremity ICPC code are presented separately. The number of consultations for neck and upper extremity complaints was calculated by the total number of consultations for (new and chronic) neck or upper extremity complaints divided by the population at risk. The number of consultations for the neck and upper extremity complaints is presented per 1000 registered patients. Finally we calculated the number of patients who consulted their GP at least once in the study year for a neck or upper extremity complaint divided by the population at risk, as an estimate of the one year prevalence. For the determination of the population at risk we used the so called mid-time population (that is, the mean of the total of registered persons at the start of the registration period and the total of registered number at the end of the registration period).

Group comparisons (men $v$ women; public $v$ private health insurance) were carried out using the binomial test procedure, with significance set at 0.01 . Owing to the large sample size we were able to use a normal approximation to the binomial distribution. We tested the null hypothesis that the two proportions were equal. 


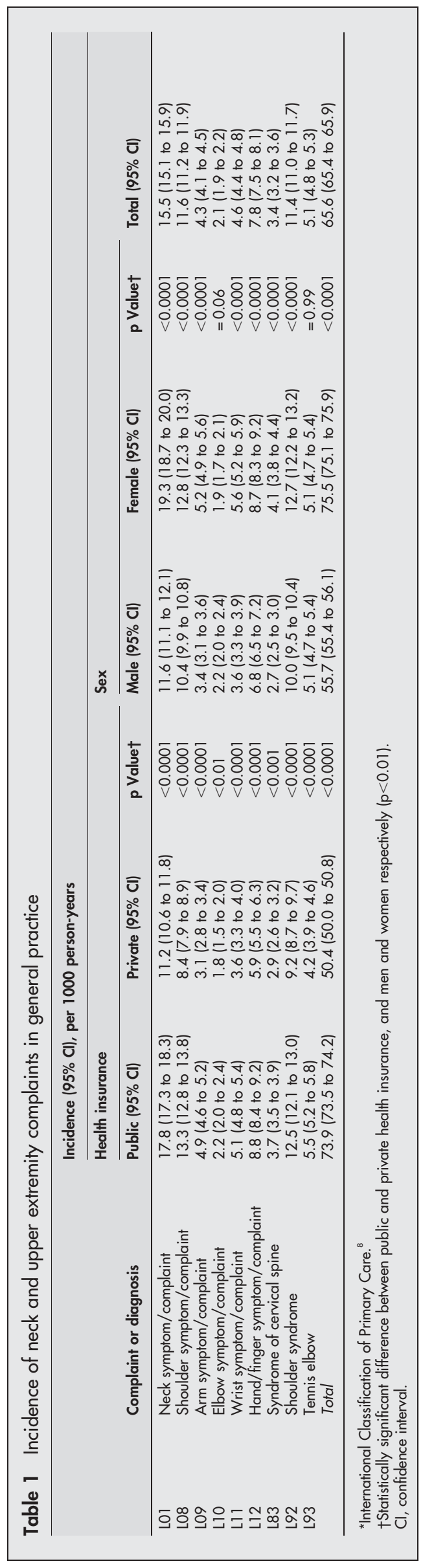

\section{RESULTS}

Two of 104 practices had not recorded any contacts, and one practice had registered for only three months of the 12 months registration period. These practices were therefore excluded from the analysis. Five additional practices had to be excluded because of the poor quality of their registration (that is, they had registered only a part of the contacts or had not coded the contacts according to the ICPC). The total number of patients registered in the remaining 96 general practices (the mid-time population) was 375 899. The total number of contacts during the registration period of one year was 1524470 .

Combining the ICPC codes of symptoms and diagnoses of the same anatomical location (that is, neck symptoms + syndrome of cervical spine; shoulder symptoms + shoulder syndrome; and elbow symptoms + tennis elbow) shows that the most commonly presenting musculoskeletal complaints in general practice were shoulder complaints (23.1 per 1000 person-years). Figure 1 gives the incidence densities of neck and upper extremity complaints for every anatomical location. The incidence density of arm, wrist, and hand complaints was relatively stable over the different age groups. A peak in elbow complaints was found in the age group 40 to 49 years.

The incidence of neck or upper extremity musculoskeletal complaints per ICPC code are presented in table 1. In table 2 we show the number of consultation for first new episodes of neck or upper extremity complaints. During the registration period, 66 GP consultations per 1000 person-years were attributable to a first new episode of a complaint of the neck or upper extremity (that is, incidence densities of ICPC codes L01, L08-L12, L83, L92-L93). In total, the GPs were consulted 55084 times ( 147 times per 1000 registered persons) for neck or upper extremity complaints. This means that in an average general practice serving a population of 2500 patients approximately 366 consultations each year concern neck or upper extremity symptoms. In total, 29588 patientsapproximately $8 \%$ (80 patients per 1000 registered persons) of all people registered-consulted their GP at least once with a complaint of the neck or upper extremity. The incidence density of, and the consultation rate for, neck and upper extremity complaints were much higher for patients with public health insurance than for privately insured patients $(p<0.01)$. Except for elbow complaints (L10, L93), the incidence densities were significantly higher for women than for men $(p<0.01)$. For both sexes, the most commonly reported complaint was neck symptoms, followed by shoulder symptoms.

The incidence of upper extremity complaints varied according to sex and age (fig 2 ). In all, $42 \%$ of the patients with a musculoskeletal complaint of the neck or upper extremity were men. The age related patterns were similar for men and women. The incidence increased up to ages of 40 to 49 years for women and 50 to 59 for men and then decreased slightly. The incidence according to ICPC codes, age, and sex are presented in table 3. The incidence of most upper extremity musculoskeletal complaints was higher for women than for men $(p<0.01)$. The incidence of tennis elbow (L93) was higher in men in the age groups 60 to 69 and 70 to 79 years $(\mathrm{p}<0.01)$.

\section{DISCUSSION}

This study provides detailed information on the incidence and prevalence of musculoskeletal complaints of the neck or upper extremity in general practice. Looking at the figures for every anatomical location (that is, a combination of ICPC codes of symptoms and diagnoses) showed that the highest incidence density was found for shoulder complaints. However, looking at the complaints per ICPC code, the 

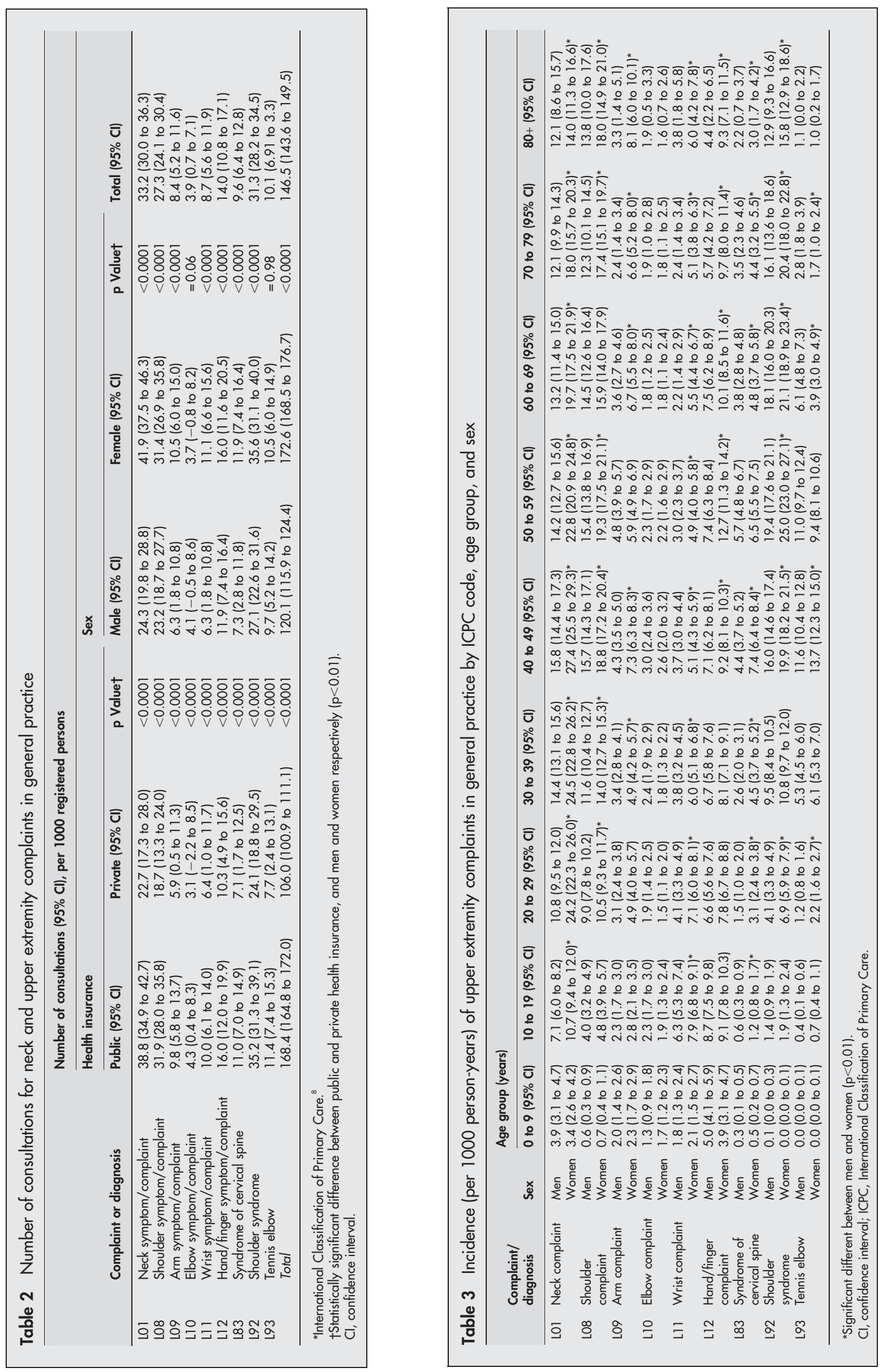
highest incidence density was found for neck symptoms (L01). It seems that the GPs use more diagnostic labels for shoulder disorders than they do for neck disorders. Rekola et $a l^{2}$ reported more people with neck complaints than shoulder complaints consulting their health centre doctor. In the general population, contrasting results can be foundeither neck complaints or shoulder complaints are more common. ${ }^{10-12}$ Differences in the type of definition used for either neck or shoulder complaints may explain the differences found. ${ }^{13}$ The incidence densities increase with higher age up to 40 to 49 years for women and 50 to 59 years for men, and then decrease slightly. Except for elbow complaints, the incidence densities were higher for women than for men. Musculoskeletal complaints, and neck and shoulder complaints in particular, are more common among women than among men. ${ }^{2-4}{ }^{14-16}$ A possible explanation of the higher incidence found among women could be that women more often have jobs characterised by static load and monotonous and repetitive tasks, and are more often exposed to additional stress from unpaid work (such as, housekeeping and child care). ${ }^{17}$ In all, approximately $8 \%$ of all people registered consulted their GP at least once with a complaint relating to the neck or upper extremity. This is slightly more than the self reported consultation figures found in the study of Picavet et al, ${ }^{1}$ in which on average $5-7 \%$ of the responders reported contact with their GP because of a neck or upper extremity complaint. Because nearly every citizen in the Netherlands is registered in a GP practice we were able to compare the figures of both studies (that is, the self reported consultation rate $=$ the incidence measured in general practice).

The way people are insured had an effect on the number of GP consultations: patients with public health insurance consulted their GP more often for upper extremity complaints than patients with private health insurance. This may be explained by the fact that patients with public health insurance are reimbursed in full for GP consultations, while private health insurance policies usually require some copayments for medical care and there may thus be a threshold for GP consultation. The public health insurance is compulsory for wage earners and social security recipients, with an annual income below a statutory ceiling (approximately $€ 32600$ ). As the type of health insurance depends on income level, it may be used as a proxy measure of socioeconomic status. Persons of lower socioeconomic status suffer more often from musculoskeletal pain ${ }^{12} 1819$ and have been shown to consult the general practitioner more often than those of high socioeconomic status. ${ }^{21} 21$ Poorer health or more strenuous working conditions may contribute to an increased incidence of neck and upper extremity complaints in these population groups. Research into the aetiology employing a more rigorous design is needed to test these hypotheses.

The highest incidence of neck and upper extremity complaints was found for patients aged 40 to 60 years. This is in agreement with other studies in general practice. ${ }^{2}{ }^{14-16}$ This finding may strengthen the assumption that there is an association between working conditions and the occurrence of neck and upper extremity complaints. Alternatively, chronic disease and other ailments may be more important in older people, and be the main reason for encountering them in general practice. Again, additional (longitudinal) research is needed to establish the association between work, age, and the occurrence of neck and upper extremity complaints.

In the first Dutch national survey of general practice in the Netherlands, 161 GPs registered every contact during three consecutive months in 1987..$^{22}$ The prevalence of neck and upper extremity musculoskeletal complaints presented in the first national survey was 50.8 per 1000 registered patients per year, ${ }^{23}$ which is much lower than the prevalence found in this second survey ( 80 per 1000 registered patients). Although the design of the second national survey resembles the first, there are several important differences. In the first survey the contacts were recorded on standardised forms instead of using computerised medical records. Second, the morbidity data were not coded by the GP, but afterwards by trained personnel. In the first survey, a modified version of the ICPC was used. These differences make it difficult to compare the results between the first and the second national survey directly, and to analyse trends over time in GP consultations for musculoskeletal complaints. Therefore it appears that the prevalence of neck and upper extremity complaints has increased over the past 13 years. This increase may at least partly be explained by the increased use of personal computers in homes and offices. ${ }^{24-26}$ Other explanations are an increase in the number of working women-the net labour participation of women increased from 35\% in 1987 to $52 \%$ in $2000^{27}{ }^{28}$-and the increased productivity demands. ${ }^{29}$

The GPs in our study used computerised patient records, which enabled calculation of accurate and detailed information about the occurrence of diseases in general practice. However, there are some limitations. The differential diagnosis the GP makes and the codes used depend on clinical judgement by the GP, experience with coding, and preferences for certain codes, which introduces some intrarater or inter-rater variation. The majority of participating GPs had been trained to use ICPC codes before the start of the study, limiting the influence of this variation on the precision of our estimates. Furthermore, when a patient had several complaints the GP may have coded only one, instead of all the complaints. Finally, for a proportion of upper extremity complaints imprecise codes may have been used-that is, codes not referring to a specific anatomical location, such as L18-L20, L28-L29, L79-L81, L88-L89, L91, L94-L95, or L98L99 (see the appendix). GPs often used imprecise ICPC codes such as "other injury musculoskeletal symptoms" (L81) and "other musculoskeletal disorder" (L99). These ICPC codes involve musculoskeletal complaints of the back, neck, upper, or lower extremity. The proportion of neck and upper extremity complaints among these and several other L codes is unknown. Thus it is most likely that the incidences found in this study for specific ICPC codes provide an underestimation of the true incidence of neck and upper extremity musculoskeletal complaints in general practice. GPs should be encouraged to use distinct and specific ICPC codes. This would improve the applicability of computerised medical records in epidemiological research, and also improve the use of computerised GP records for obtaining indicators of care in specific patient groups, or for other more practical purposes.

The incidences found in this study inform us about the number of people with musculoskeletal complaints of the neck or upper extremity that are serious, painful, or annoying enough to seek medical care. In other countries, besides consulting a GP, people may seek a specialist's opinion directly, or visit a health centre or hospital with their complaint. In the Netherlands, every Dutch resident has their own GP. Patients first see their GP before going to a specialist. This is comparable to, for instance, the British and Canadian healthcare systems. Thus the results found in our study provide a good estimate of the number of people with neck and upper extremity musculoskeletal complaints seeking medical care.

The impact of neck and upper extremity complaints on the workload of GPs contrasts with the small amount of time that is dedicated to these problems in the training of medical students and the vocational training of GPs. Furthermore, very little research has been done on the prognosis and treatment of these complaints in general practice. More 
research is needed to study the prognosis and management of neck and upper extremity disorders in general practice.

\section{Conclusions}

Neck and upper extremity musculoskeletal complaints are common in Dutch general practice. The GP is consulted approximately seven times a week for neck or upper extremity complaints.

\section{Authors' affiliations \\ S D M Bot, J M van der Waal, C B Terwee, L M Bouter, Institute for Research in Extramural Medicine, VU University Medical Centre, Amsterdam, Netherlands \\ D A W M van der Windt, Department of General Practice, VU University Medical Centre \\ F G Schellevis, Netherlands Institute for Health Services Research, Utrecht, Netherlands \\ J Dekker, Department of Rehabilitation Medicine, VU University Medical Centre}

\section{APPENDIX}

\section{INTERNATIONAL CLASSIFICATION OF PRIMARY CARE (ICPC) CODES}

(ICPC codes selected for inclusion in the present study are shown in italic and bold)

- L01: Neck symptoms/complaints

- L08: Shoulder symptoms/complaints

- L09: Arm symptoms/complaints

- L10: Elbow symptoms/complaints

- L11: Wrist symptoms/complaints

- L12: Hand/finger symptoms/complaints

- L13: Hip symptoms/complaints

- L14: Leg/thigh symptoms/complaints

- L15: Knee symptoms/complaints

- L16: Ankle symptoms/complaints

- L17: Foot/toe symptoms/complaints

- L18: Muscle pain/fibrositis

- L19: Other symptoms, multiple/unspecified muscle

- L20: Symptoms multiple/unspecified joints

- L28: Disability/impairment

- L29: Other \& multiple musculoskeletal symptoms

- L77: Sprain of ankle/foot

- L78: Sprains/strains of knees

- L79: Sprains/strains other joints

- L80: Dislocations

- L81: Other injury musculoskeletal

- L83: Syndrome of cervical spine

- L84: Osteoarthritis spine

- L85: Acquired deformities of spine

- L87: Ganglion joint/tendon

- L88: Rheumatoid arthritis

- L89: Osteoarthritis hip

- L90: Osteoarthritis knee

- L91: Other osteoarthritis

- L92: Shoulder syndrome

- L93: Tennis elbow

- L94: Osgood-Schlatter, osteochondritis

- L95: Osteoporosis

- L96: Acute meniscus/ligament knee

- L97: Chronic internal knee derangement
- L98: Acquired deformities limbs

- L99: Other musculoskeletal/connective disorder

\section{REFERENCES}

1 Picavet HS, Schouten JS. Musculoskeletal pain in the Netherlands: prevalences, consequences and risk groups, the DMC(3) study. Pain 2003; 102:167-78.

2 Rekola KE, Keinanen-Kiukaanniemi S, Takala J. Use of Primary Health Services in Sparsely Populated Country Districts by Patients With musculoskeletal symptoms: consultations with a physician. J Epidemiol Community Health 1993;47:153-7.

3 Nialsson T, Sigurdsson JA, McAuley RG. Health problems in family practice. An Icelandic multicentre study. Scand J Prim Health Care 1996;14:4-12.

4 McCormick A, Fleming D, Charlton J. Morbidity statistics from general practice. Fourth national study 1991-1992, series MB5 No 3. London: HMSO, 2004.

5 CBS. www.cbs.nl/en/publications/articles/webmagazine/2002/1080.htm.

6 Westert GP, Schellevis FG, de Bakker DH, Groenewegen PP, Bensing JM, van der Zee J. Monitoring health inequalities through general practice: the second Dutch national survey of general practice. Eur J Public Health (in press).

7 Schellevis FG, Westert GP, de Bakker DH, Groenewegen PP, van der Zee J, Bensing JM. De Tweede Nationale Studie Naar Ziekten En Verrichtingen in De Huisartsenpraktiik: Aanleiding En Methoden. Huisarts en Wetenschap 2003;46:7-12.

8 Lamberts H, Wood M, eds. International classification of primary care. Oxford: Oxford University Press, 1987.

9 van der Linden MW, Westert GP, de Bakker DH, Schellevis FG. Tweede Nationale Studie naar ziekten en verrichtingen in de huisartspraktiik. Klachten en aandoeningen in de bevolking en in de huisartspraktijk. Utrecht/Bilthoven: NIVEL/RIVM, 2004.

10 Andersson HI, Ejlertsson G, Leden I, Rosenberg C. Chronic pain in a geographically defined general population: studies of differences in age, gender, social class, and pain localization. Clin J Pain, 19931909, 174-82.

11 Picavet HS, Hazes JM. Prevalence of self reported musculoskeletal diseases is high. Ann Rheum Dis 2003;62:644-50.

12 Urwin M, Symmons D, Allison T, Brammah T, Busby $H$, Roxby M, et al. Estimating the burden of musculoskeletal disorders in the community: the comparative prevalence of symptoms at different anatomical sites, and the relation to social deprivation. Ann Rheum Dis 1998;57:649-55.

13 Pope DP, Croft PR, Pritchard CM, Silman AJ. Prevalence of shoulder pain in the community: the influence of case definition. Ann Rheum Dis 1997;56:308-12.

14 Hasselstrom J, Liu-Palmgren J, Rasjo-Wraak G. Prevalence of pain in general practice. Eur J Pain 2002;6:375-85.

15 Kerssens JJ, Verhaak PF, Bartelds Al, Sorbi MJ, Bensing JM. Unexplained severe chronic pain in general practice. Eur J Pain 2002;6:203-12.

16 Mantyselka P, Kumpusalo E, Ahonen R, Kumpusalo A, Kauhanen J, Viinamaki $H$, et al. Pain as a reason to visit the doctor: a study in Finnish primary health care. Pain 2001;89:175-80.

17 Lundberg U. Psychophysiology of work: stress, gender, endocrine response, and work-related upper extremity disorders. Am J Ind Med 2002; 1941:383-92.

18 Bergman S, Herrstrom P, Hogstrom K, Petersson IF, Svensson B, Jacobsson LT. Chronic musculoskeletal pain, prevalence rates, and sociodemographic associations in a Swedish population study. J Rheumatol 2001; 1928:1369-77.

19 Brekke M, Hjortdahl P, Kvien TK. Severity of musculoskeletal pain: relations to socioeconomic inequality. Soc Sci Med 2002;1954:221-8.

20 Van der Heyden JH, Demarest S, Tafforeau J, Van Oyen H. Socio-economic differences in the utilisation of health services in Belgium. Health Policy 2003;65: 153-65.

21 van der Meer JB, van den Bos J, Mackenbach JP. Socioeconomic differences in the utilization of health services in a Dutch population: the contribution of health status. Health Policy 1996;37:1-18.

22 Foets M, van der Velden J, de Bakker D. Dutch national survey of general practice: a summary of the survey design. Utrecht: Institute of Primary Health Care (NIVEL), 1992

23 van der Velden J, de Bakker DH, Claessens AAMC, Schellevis FG Basisrapport: Morbiditeit in De Huisartspraktiik. Een Nationale Studie Naar Ziekten En Verrichtingen in De Huisartspraktijk. Utrecht: Institute of Primary Health Care (NIVEL), 1991

24 Gerr F, Marcus M, Ensor C, Kleinbaum D, Cohen S, Edwards A, et al. A prospective study of computer users. I. Study design and incidence of musculoskeletal symptoms and disorders. Am J Ind Med 2002;41:221-35.

25 Jensen $C$. Development of neck and hand-wrist symptoms in relation to duration of computer use at work. Scand J Work Environ Health 2003;29:197-205

26 Ortiz-Hernandez L, Tamez-Gonzalez S, Martinez-Alcantara S, MendezRamirez I. Computer use increases the risk of musculoskeletal disorders among newspaper office workers. Arch Med Res 2003;34:331-42.

27 CBS. http://statline.cbs.nl.

28 Yassi A, Sprout J, Tate R. Upper limb repetitive strain injuries in Manitoba. Am J Ind Med 1996;1930:461-72.

29 Brogmus GE, Sorock GS, Webster BS. Recent trends in work-related cumulative trauma disorders of the upper extremities in the united states: an evaluation of possible reasons. J Occup Environ Med 1996;1938:401-11. 